\title{
LOS TÍTERES Y LAS MARIONETAS EN EL CONTEXTO ARTÍSTICO DE MANUEL DE FALLA
}

\section{MUPPETS AND MARIONETTES IN MANUEL DE FALLA'S ARTISTIC CONTEXT}

\author{
Ana Arcas Espejo \\ Escuela Superior de Arte Dramático de Sevilla. España \\ ORCID: 0000-0002-9287-7787 \\ arcas.espejo@gmail.com
}

\begin{abstract}
El presente artículo aborda las experiencias de Manuel de Falla con el ámbito del títere de su época. A través de ello se pretende esclarecer cuáles fueron las influencias escénicas del músico, al mismo tiempo que encontramos la génesis de grandes obras de su repertorio como El retablo de maese Pedro. Por otra parte, se pretende revisar y poner en valor la aportación de Manuel de Falla al ámbito del títere español. El cuál, sin perder su esencia, que hunde sus raíces en la tradición del teatro de títeres de cachiporra, comulga con los postulados del teatro de vanguardia europeo invitando a volver la mirada hacía sus orígenes.

Palabras clave: escenografía; títeres; teatro; vanguardia; Manuel de Falla.
\end{abstract}

This article disserts about Manuel de Falla's experiences with the art of puppetry during his lifetime. Such collaborations help us understand not only the scenographic influences in the artistic language of the composer, also the genesis of several master pieces from his repertoire, such as El retablo de maese Pedro. On the other hand, it is intended to review and value the contribution of Manuel de Falla to the field of the Spanish puppetry. Which, without losing its essence, has its roots in the tradition of the blackjack puppet theater, while at the same time communes with the postulates of the European avant-garde theater, inviting us to look back at its origins.

Keywords: scenography; puppetry; theatre; avant-garde; Manuel de Falla.

El mundo de los títeres fue, en el contexto artístico de Manuel de Falla, un punto de partida y catalizador de una época de profunda renovación del ámbito teatral europeo, que encontró en esta manifestación popular de índole escénica el mejor referente posible como fuente inagotable de inspiración. 
A lo largo de los anteriores siglos, formar parte de la tradición titiritera generalmente era debido a la existencia de un legado artístico familiar, que se transmitía a lo largo de las diversas generaciones mediante los espectáculos que tradicionalmente se desarrollaban en plazas, ferias o lugares públicos. Muchas de estas prácticas, como la de los puppis sicilianos, gozaban de buena salud en los albores del siglo xx, aunque muchas otras, como la del dom Roberto portugués o su correlativo español don Cristóbal, habían prácticamente desaparecido ${ }^{1}$.

La puesta en valor del género de los títeres en esta época dentro del ámbito escénico se debió eminentemente a la decidida apuesta de artistas procedentes de diversas disciplinas, no siempre titiriteros profesionales per se. La ausencia de una profesionalización especifica permite una libertad creativa que no se debe a tradiciones decimonónicas, lo que nos lleva a observar la convivencia de manifestaciones vinculadas al mundo del títere que protagonizan artistas de fama internacional como Picasso o Alexandra Exter, en obras de teatro o cine respectivamente. Otros artistas fabricarán títeres geométricos y de funcionalidad eminentemente mecánica, como los futuristas Fortunato Depero o Enrico Prampolini, partiendo de encargos puntuales para Vittorio Podrecca. Muchos de estos creadores buscarían reivindicar el títere como ente artístico dentro de otros géneros escénicos, mientras que una minoría llegaría incluso a fundar sus propias compañías titiriteras ${ }^{2}$.

La existencia de este abanico de artistas multidisciplinares enriquece de modo incontestable el mundo de los títeres y sirve de impulsor para su evolución, ampliando su temática y su repertorio dramatúrgico y literario, además de sus técnicas constructivas y escenográficas. Se podría establecer, grosso modo, que el títere se profesionaliza, abandonando su recinto tradicional y su relación casi paternofilial con su creador y manipulador.

La tradicional consideración como una disciplina de menor rango en el ámbito escénico se revierte plenamente y los títeres, huérfanos de padres artistas con pretensiones y ávidos de reconocimiento internacional, muestran que en ellos se encuentra la verdadera esencia de un arte escénico y plástico carente de fedatarios celosos en la perpetuación de una tradición.

Esta marginalidad no había desvirtuado los primigenios esquemas dramáticos, lo que les confiere una inigualable capacidad para transmitir al espectador, de forma directa y sin las interferencias de una tradición teatral aburguesada y excesivamente costosa, un microcosmos de experiencias que trascienden un mero

${ }^{1} \mathrm{http} / /$ www.titeresante.es/2016/08/18/la-europa-de-las-vanguardias-proyecto-allstrings-attached-klemencic-podrecca-y-lanz-pioneros-de-los-titeres-europeos-por-yanisb (27/04/2021).

${ }^{2} \mathrm{http} / / / \mathrm{www} . t i t e r e s a n t e . e s / 2016 / 08 / 18 /$ la-europa-de-las-vanguardias-proyecto-allstrings-attached-klemencic-podrecca-y-lanz-pioneros-de-los-titeres-europeos-por-yanisb (27/04/2021). 
texto llevado a la escena. No podemos por lo tanto intentar adentrarnos en el contexto cultural de esta época sin mencionar a creadores como Valle-Inclán, Rafael Alberti, Cipriano Rivas Cherif, Manuel de Falla, Federico García Lorca, Ignacio Zuloaga, Hermenegildo Lanz o Salvador Bartolozzi, obviando un aspecto común a todos ellos, como era su admiración e interés sincero por vincular su arte al mundo de los títeres.

A lo largo de su vida, Falla recordó en numerosas ocasiones momentos de la infancia que protagonizaron su hermana y él en Cádiz, donde asistieron a espectáculos de marionetas sicilianas y donde regularmente jugaban con un teatro de marionetas en el cual don Quijote y sus aventuras eran un tema recurrente. Según le expresó a uno de sus biógrafos, Jaime Pahissa, Falla tenía una particular afición, desde su infancia, por los juegos con un teatrito de muñecos en el cual representaba historias que él mismo creaba ${ }^{3}$. Del mismo modo, Leónide Massine, en una serie de reflexiones sobre Falla, describía cómo el compositor gaditano estaba fascinado por las marionetas y los pequeños teatros de muñecos, y cómo él mismo había escrito en su infancia una obra de teatro basada en don Quijote para su teatro de marionetas ${ }^{4}$. Quizá en estas ingenuas experiencias infantiles encontramos la génesis de El retablo de maese Pedro, partiendo de las siguientes líneas en una carta a Roland-Manuel:

... No obstante mi vocación, a pesar de mi amor por ciertas músicas (¡no todas!), siempre se inclinaba hacia el lado literario (a la prosa, no al verso). A ello se sumaba mi gusto por la historia; sobre todo la historia de España, en la que yo encontraba una especie de espléndida continuación de antiguas leyendas que encantaron mi primera infancia. [...] Agreguemos aún mis representaciones en un pequeño teatro de marionetas cuyo único público era mi hermana, y en el que don Quijote y sus aventuras ocupaban un lugar de predilección...5

Manuel de Falla, en esta etapa infantil, era también un asiduo espectador de los espectáculos titeriles de la Feria del Frío, desarrollados por el Teatro de la Tía Norica, la compañía de teatro con muñecos articulados con más tradición en España.

La idea de llevar a la escena algún pasaje de Don Quijote fue algo que de alguna forma Falla tuvo en su mente hasta la recepción de un encargo escénico el 25 de octubre 1918 por parte de la Princesa de Polignac. Muestra de ello es su interés por la gestación de Las figuras del Quijote, obra de su amigo y colaborador gaditano, el poeta y libretista de La vida breve, Carlos Fernández Shaw, como muestran los siguientes extractos de su prolija correspondencia en esta época:

\footnotetext{
${ }^{3}$ Pahissa, 1947: 25.

${ }^{4}$ Christoforidis, 1997: 99.

${ }^{5}$ Porras Soriano, 1995: 17.
} 
Muy querido don Carlos:

En cuanto a Figuras del Quijote, le aseguro que me entusiasma grandemente. ¡Eso es hacer obra española!... ${ }^{6}$

... No deje de darme noticias de los estrenos que prepara. Tengo gran deseo y curiosidad por conocer sus Figuras del Quijote... ${ }^{7}$

Mientras tanto, el mundo del títere empezaba a ganar terreno dentro del ámbito escénico tradicional, comenzando a formar parte de las actuaciones de cupletistas, del teatro de variedades, y creándose publicaciones especializadas como Titella, publicada en Barcelona. Incluso llegó a ahormarse un proyecto educativo nacional para la implantación de funciones titiritescas en el sistema de enseñanza oficial, aunque finalmente quedaría en mero proyecto piloto sin consolidación de facto $^{8}$.

Manuel de Falla recupera estas vivencias infantiles tras instalarse en Granada en 1920 y gozar de una afectuosa e intensa convivencia artística casi paterno-filial con Lorca. Los primeros contactos entre ambos tienen como escenario las tertulias de El Rinconcillo, un selecto grupo de intelectuales residentes en Granada. Entre los múltiples proyectos para revitalizar la vida cultural de la ciudad nazarí, soñaban con la creación de una compañía que se denominaría Títeres de Cachiporra. Los impulsores de esta idea fueron Lanz y los músicos Adolfo Salazar y Ernesto Halffter, además de Falla y Lorca. Los dos últimos estaban en esa época inmersos en la gestación de sendas obras, que a la postre incorporarían el mundo de los títeres como parte esencial de las mismas. En el caso de Lorca, el resultado se tituló El maleficio de la mariposa (en un primer momento La ínfima comedia),

${ }^{6}$ Carta de Falla a Carlos Fernández Shaw, París, 28 de abril de 1910, Archivo Manuel de Falla (AMF), (carpeta de correspondencia 6973).

En el AMF se han revisado las siguientes carpetas de correspondencia:

M. Falla - Manuel Ángeles Ortiz (carpeta correspondencia 6704).

M. Falla - Federico García Lorca (carpeta de correspondencia 7022).

M. Falla - María y Gregorio Martínez Sierra (carpeta de correspondencia 7251).

M. Falla - Pablo Picasso (carpeta correspondencia 7418).

M. Falla - Princesa de Polignac (carpeta correspondencia 7432).

M. Falla - Rivas Cherif (carpeta de correspondencia 7497).

M. Falla - Ignacio Zuloaga (carpeta de correspondencia 7797 y 7798 ).

M. Falla - Hermenegildo Lanz (carpeta de correspondencia 7929).

${ }^{7}$ Carta de Falla a Carlos Fernández Shaw, París, 31 de mayo de 1910, AMF (carpeta de correspondencia 6973).

8 Porras Soriano, 1995: 35-36.

9 Sobre la figura de Lanz y sus colaboraciones con Manuel de Falla véase: Soria Ortega, 2000: 393-404. Malipiero/Soria Ortega/Sopeña Ibáñez, 1983: 1-162. 
denostada por Martínez Sierra en cuanto a la inclusión de los títeres, y El retablo de maese Pedro en el caso de Falla.

Tanto Falla como Lorca indudablemente eran conocedores de las vanguardias europeas y los movimientos de recuperación de la tradición titiritesca en el ámbito escénico, con lo que a buen seguro este fue tema de conversación en las mencionadas tertulias. El mundo de los títeres pertenecía a una tradición decimonónica española vinculada a teatrillos ambulantes que viajan por los pueblos y ciudades de feria en feria, con personajes similares a los que aparecen en el guiñol francés. Concretamente, Lorca mostró un interés especial en la tradición de los títeres denominados "los cristobicas", desarrollando una serie de actuaciones que tenían como fin la recuperación de este patrimonio.

Los espectáculos callejeros, que despiertan nuevamente este interés de Falla por el mundo de los títeres, lo mismo que el de su amigo Lorca y de otros artistas del círculo granadino, seguían siendo habituales en el entorno rural a principios del siglo xx, lógicamente imperando una tradición oral en los textos seleccionados. Falla y Lorca mostraron un sincero interés en estudiar y recuperar dicha tradición, particularmente sobre las prácticas titiritescas de la zona de la Alpujarra granadina, donde planearon una serie de viajes con objeto de documentarse in situ sobre esta manifestación popular. De este modo manifestaría Lorca su entusiasmo a Falla con relación a este proyecto:

Queridísimo Don Manué:

Estoy entusiasmado con el proyecto de viaje a la Alpujarra. Ya sabe usted la ilusión tan grande que tengo de hacer unos Cristobical llenos de emoción andaluza y exquisito sentimiento popular.

Creo que debemos hacer esto muy en serio; los títeres de cachiporra se prestan a crear canciones originalísimas. Hay que hacer la Tragedia (nunca bien alabada) del caballero de la flauta y el mosquito de trompetilla, el idilio salvaje de don Cristobal y la señá Rosita, la muerte de Pepe Hillo en la plaza de Madrid y algunas otras farsas de nuestra invención [...]. En el pueblo, no hace muchos días, hubo un tío con unos cristobicas que se metían con todo el mundo de una manera aristofanesca... ${ }^{10}$

De esta forma, animado por Lorca, Falla también decidió explorar este medio. El interés de Falla por adentrarse en esta tradición dentro de su obra musical no decaería durante años. Otro activo participante en el proceso de recuperación de esta tradición fue Salazar, que anhelaba que dichas manifestaciones populares de muñecos pudieran adaptarse y programarse en los grandes teatros europeos.

El primer acto del grupo de artistas residentes en Granada relacionado con esta iniciativa fue la representación con títeres de cachiporra en la casa de la

${ }^{10}$ Carta de Lorca a Falla, Granada, 18 de julio de 1922, AMF (carpeta de correspondencia 7022). 
familia Lorca, que tuvo lugar el 6 de enero de 1923. Federico quería convertir este acto en un regalo a su hermana Isabel con motivo de la Festividad de los Reyes Magos $^{11}$. Los asistentes pudieron contemplar tres números escénicos en los que Falla dirigió la música con obras de Claude Debussy, Isaac Albéniz, Maurice Ravel y Felipe Pedrell, además de un arreglo del propio Falla extraído de la Historia del Soldado de Ígor Stravinsky para el entremés cervantino.

Entre la correspondencia de febrero de 1923 encontramos una carta de $\mathrm{Zu}$ loaga a Falla en la que hace referencia a la fiesta de títeres para niños que se realizó en casa del padre de Lorca y que, por su momento cronológico, se convierte en un ensayo general del teatro de títeres que después culminaría con El retablo: "La fiesta artística por excelencia que organizó Vd. para los niños, debió ser sensacional. Bravo! Así se hace cultura"12. Falla debía estar ilusionado con el proyecto a juzgar por su correspondencia, en la que se recogen numerosas invitaciones a amigos y colaboradores cercanos:

¿Recibió usted un programa que le envié de nuestros Títeres de Cachiporra? Si este verano viene usted a Granada presenciará usted alguna representación y espero será muy de su gusto... ${ }^{13}$

El programa ${ }^{14}$ original al que se refiere Falla puede consultarse en el Archivo Manuel de Falla y es descrito por Ian Gibson con las siguientes palabras:

En su portada, debajo del dibujo de un guitarrista andaluz del siglo XIX, leemos Títeres de Cachiporra (Cristobica). Dentro del pliego, sin duda alguna redactado por el poeta [Lorca] —y luego leído por él al principio de la función-, «El Dueño del Teatrillo» anuncia, con profusión de detalles y variada tipografía, las obras que se estrenarán en tan notable ocasión, y señala que la música que acompañe a estas será ejecutada por Manuel de Falla (piano y cémbalo), José Gómez (violín), Alfredo Baldrés (clarinete) y José Malina (laúd) ${ }^{15}$.

En este evento se representaron el entremés de Miguel de Cervantes Los dos habladores; La niña que riega la albahaca y el príncipe preguntón, en una adaptación de Lorca. Terminó el acto con la escenificación del auto sacramental del siglo XIII El misterio de los Reyes Magos. Falla selecciona la música y la interpreta en un piano cuyas cuerdas se forran de papel de seda para imitación del sonido de un clave, recurso que tiene una conexión directa a la adaptación que se hacía

${ }^{11}$ AA.VV., 1993: 6.

${ }^{12}$ Carta de Zuloaga a Falla, París, 24 de febrero de 1923, AMF (carpeta de correspondencia 7798).

${ }_{13}^{13}$ Falla/Trend, 2007: carta de Falla a John B. Trend, Granada, 6 de marzo de 1923.

${ }_{14}$ Programa de mano, 6 de enero de 1923, AMF, 1923-7, FN.

15 Gibson, 1985: 335. 
del piano cuando no había un clave y a la predilección de Falla por el sonido de este instrumento. El carácter aparentemente intrascendente de este pequeño concierto no fue tal, puesto que la selección musical que había realizado Falla incluía estrenos en España de fragmentos de la Historia del soldado de Stravinsky y composiciones de Debussy o Ravel, combinadas con fuentes musicales procedentes de los cancioneros históricos, muestra inequívoca de las influencias musicales de Pedrell en su discípulo.

Lorca sería el manipulador de los diversos títeres junto a su hermana Concha, con entreactos en los que don Cristóbal, uno de los muñecos que protagonizaban el acto, intercalaba diálogos jocosos con los niños y adultos asistentes. Falla coordinó todos los aspectos musicales del espectáculo, que, aunque en sí mismo no fuera concebido más que como un acto privado, sí quedó inmortalizado a nivel gráfico y con reseñas en prensa. Lorca vio cumplido a través de este proyecto su deseo de colaborar con Falla, creando la base de lo que sería su proyecto teatral de Títeres Españoles. José Francés reseñó el acto en el semanario $L a$ Esfera de Granada, bajo el título "Los bellos ejemplos. En Granada resucita el guignol", acompañando sus palabras de cuatro fotografías, tres de la propia representación y una de varios títeres de guante protagonistas, entre ellos el de don Cristóbal, manipulado por Lorca y mencionado anteriormente:

A este generoso propósito de que despierte el íntimo adormecido responde el Teatro Guignol, que un poeta joven y ya dotado de eficaz respeto en torno suyo, como García Lorca; que un músico de universal renombre, como Manuel de Falla, han inaugurado en Granada... ${ }^{16}$

Esta sesión de títeres en la casa de la familia Lorca sirvió como relevante campo de experimentación para la idea escénica que Falla plantearía en El retablo, implicándose del mismo modo el escenógrafo Lanz en la fabricación del decorado y las figuras intervinientes, aspecto que ya anticiparía de algún modo Mora Guardino en su artículo de $L a V o z$ al reseñar este espectáculo titiritesco ${ }^{17}$ :

El teatro guiñol español es de una gran antigüedad. El «maese Pedro», de Cervantes, llevaba ya un retablo perfecto, indicador de un arte muy maduro, popular y culto a la vez. Pero la manifestación culta de este arte se desvanece en la Historia y permanece, en cambio, la manifestación popular, cristalizando en un personaje típico: «Cristobicas», que es un Falstaff, cuyo espíritu espera a un poeta que le concrete y le dé forma de tipo humano. «Cristobicas», el bufón popular del guiñol español, lleva un traje rojo, cascabeles y una gran porra. Esta gran porra es el símbolo de su justicia inapelable. Con ella da en la cabeza a todo el que con razón o sin razón se opone a su voluntad [...]. Otros personajes del guiñol son: «la señá Rosita», que unas veces es joven, ingenua y preciosa y otras vieja alcahueta, $\mathrm{y}$ «Currito el del Puerto», que siempre

\footnotetext{
${ }^{16}$ Francés: 1923.

${ }_{17}$ Miermont/Gobin, 2003: 69.
} 
hace de galán [...]. La fiesta de Reyes de casa del poeta García Lorca, objeto de este artículo, es también, puede decirse, el primer acto de reivindicación culta del teatro de «Cristobicas» ${ }^{18}$.

Otra de las crónicas del estreno, al igual que la anterior de José Mora Guardino, aporta interesante información sobre el desarrollo escenográfico del evento, además de anticipar futuras colaboraciones en el ámbito titiritesco entre Lorca, Falla y Lanz:

Son ciento cincuenta figuras las que componen las diferentes escenas: los Reyes de Oriente y sus cortejos, la Corte de Herodes, la súplica de las madres desoladas por el decreto de degollación de los Inocentes... Todas ellas se mueven en un ambiente fantástico. $\mathrm{O}$ bajo un cielo azul intenso, en el cual brilla la estrella milagrosa del aviso, o un campo de quebradas perspectivas, árboles raros, cielo de oro y con una ciudad ideal al fondo, donde la caravana final de los Reyes se pierde, en tanto que se oyen villancicos lejanos.

(Mientras las escenas de la representación se sucedían, la orquestilla del maestro Falla tocaba con címbalo, clarinete y laúd, dos Cantigas de Alfonso el Sabio).

Hermenegildo Lanz, animado por el éxito de su primer ensayo, proyecta unos aguafuertes escenográficos de guiñol: el primero, escenas de brujas en la noche; el segundo, una feria de pueblo. Ambos se incorporarán al repertorio planista del Teatro Cachiporra Andaluz ${ }^{19}$.

En el Archivo Lanz se conserva un escrito de Hermenegildo titulado Marionetas, que realiza una perfecta radiografía de lo sucedido en la mencionada representación de títeres, y que sirve como muestra de la vocación continuista que tuvo este proyecto:

Durante el año 1922 y en el día de Reyes de 1923 un gran músico, un gran poeta y un pintor construyeron expresamente y lo representaron en Granada, el teatro de muñecos más sugestivo e interesante de los que hasta el presente se han exhibido por los escenarios españoles. Inspirado en la tradición del inquieto Cristobica, genuino personaje andaluz, al frente de su «compañía», bajo la dirección del «empresario $\mathrm{Cu}$ rrito del Puerto» que innovó las costumbres con una representación de teatro planista de más de trescientas figuras, además de su elenco corpóreo, resultó ser un prolegómeno de lo que en el mismo año ( 25 de junio) había de estrenarse en París con el nombre de El retablo de maese Pedro. De aquel teatrito solo se hizo una representación y obtuvo un éxito extraordinario y fue el principio serio, muy serio, de intentos varios en otras regiones nacionales y extranjeras destacando posteriormente hacia $1927 \mathrm{o}$ 1928 las representaciones de muñecos actores del «grupo de artistas y literatos berlineses» que con el mismo sistema de muñecos recortados, articulados del modo como

\footnotetext{
18 Mora Guardino, 1923.

19 Mora Guardino: 1923.
} 
se hizo en Granada y en París, interesó al público alemán en varias exhibiciones breves pero selectas ${ }^{20}$.

El títere don Cristóbal (Figura 1) ejercía el papel de presentador en homenaje a las representaciones populares que Lorca y Falla habían visto en su infancia. Más allá del carácter familiar y entrañable de este montaje, Lorca tenía la firme intención de recuperar el tradicional teatro de cachiporra andaluz y Manuel de Falla la de experimentar la combinación entre música, títeres y diálogo, con vistas al encargo de El retablo de maese Pedro ${ }^{21}$. Este formato teatral, que recuperaba el protagonismo de la figura de la marioneta o el títere, era muy del gusto de la vanguardia teatral europea. Renovadores de la escena como Alfred Jarry, Gordon Craig, Oskar Schlemmer, Vsévolod Meyerhold o Maurice Maeterlinck buscarían salir del convencionalismo del teatro burgués y renovar el mundo de la escena partiendo de este medio ${ }^{22}$. Por otra parte, la elección de la técnica de teatro planista para El misterio de los Reyes Magos no fue casual, sino que reutiliza un recurso del antiguo teatro de títeres partiendo de la iconografía medieval y sirvió como experiencia previa para las figuras de la historia de Melisendra en El retablo:

El Misterio de los Reyes Magos se representó con los principios del teatro de papel. Este divertimento de origen editorial, surgido en Inglaterra en el siglo XIX, es instaurado en España a partir de 1865 a través de la Estampería Paluzie; no era aún algo habitual como práctica escénica, como sí se conoce en la actualidad. Utilizar los principios del teatro de papel aumentando su escala —el telón de fondo debió de tener aproximadamente noventa centímetros de alto por ciento veinte centímetros de ancho, los personajes entre veinte y treinta centímetros-, fue algo muy innovador. Partir de una obra plana medieval y darle una dimensión escenográfica, ponerla en movimiento y enriquecerla con música, canto e iluminación, fue una apuesta revolucionaria en el teatro de títeres español ${ }^{23}$.

Lanz fue el encargado de toda esta escenografía, construyendo el pequeño teatro, que Francisco García Lorca describiría para El misterio de los Reyes Magos como de "no más de metro y medio de ancho, y el telón hecho de dos pañuelos populares en rojo y blanco, de los que llaman «de sandía»" 24 . A pesar de tratarse de un estreno de carácter familiar y lúdico, Lanz trabajó con gran dedicación, como muestra una carta a su familia:

Con el gran maestro M. de Falla y el poeta F. G. Lorca y yo hemos formado el teatro guiñol andaluz con la intención de perfeccionarlo y llevarlo al extranjero, visto

${ }^{20}$ Hermenegildo Lanz, borrador original manuscrito, Granada, Archivo Lanz (AL).

${ }^{21}$ Mata, 2003: 25-26.

${ }^{22}$ Mata, 2003: 26-27.

${ }^{23}$ Martínez, 2012: 32.

${ }^{24}$ AA.VV., 1993: 8. 
el éxito enorme que ha tenido su estreno y presentación [...]. Este programa tiene dos partes, de la primera son mías las decoraciones y las cabecitas que he tallado y pintado y la segunda, o sea el teatro planista, soy autor de la decoración y las ciento cuarenta figuras que han representado el milagro de los Reyes Magos... ${ }^{25}$.

También participó Lanz pintando los decorados, tallando primorosamente las cabezas de los títeres, que no superaban los diez centímetros de tamaño, y diseñando el vestuario, de cuya confección se encargaría la madre de Lorca (Figura 1) y en los que logra una factura muy vanguardista, de inspiración cubista. Además, recorta y pinta con gran detalle en torno a ciento cincuenta figuras planistas (Figura 2) con decorados que estaban inspiradas en el códice De natura rerum (Codex Granatensis), conservado en la Universidad de Granada ${ }^{26}$.

El teatrito construido por Lanz mostraría en la parte frontal tres pavos reales de corte modernista, adornando los laterales dos jarrones que contienen la inscripción de "teatro de los niños", de los que emergen flores esquematizadas que parecen libar dos libélulas. Este telón sería regalado por Lanz a Isabel García Lorca, algo que recordaría toda su vida ${ }^{27}$.

Casi con toda seguridad, el primer impresionado del talento escenográfico y versatilidad de Lanz a la hora de acometer diversas disciplinas de índole artística para llevar a cabo esta escenografía fue Manuel de Falla, lo que justificaría el hecho de solicitar con carácter de urgencia que se encargase de llevar a cabo las cabezas y manos de los muñecos protagonistas de El retablo, así como varias de las figuras planas y los bocetos de decorado de los cuadros segundo y quinto de la obra, correspondientes a la torre en la que Melisendra se encuentra cautiva. Así se lo hace saber a Lanz en una carta enviada desde París el 28 de abril de 1923:

Creo darle una buena noticia al decirle que la Princesa de Polignac — como consecuencia de nuestra conversación - desea que haga Ud las cabezas y manos (con la forma que Ud sabe) de los muñecos de guiñol para el Retablo, (cuyo estreno tendrá lugar en su casa el 8 de junio) y además el boceto para la decoración del cuadro segundo, o sea el de la Torre de Melisendra.

Madame de Polignac le invita a Ud (con todas las consecuencias de la invitación, o sea los gastos de viaje y estancia en París) para que venga Ud desde unos días antes del estreno y hasta que terminen las representaciones. Figúrese Ud con cuanta alegría pienso esta continuación parisina de nuestros trabajos cachiporrísticos de Granada... ${ }^{28}$.

${ }^{25}$ Carta de Hermenegildo Lanz a su familia, Granada, 14 de enero de 1923, (AL).

${ }^{26}$ Mata, 2003: 29.

27 Castillo Higueras, 1994: 13-15.

${ }^{28}$ Carta de Falla a Lanz, París, 28 de abril de 1923, AMF (carpeta de correspondencia 7929). 
A este respecto, Falla comunica en esa misma carta una serie de instrucciones muy precisas a Lanz sobre sus requisitos y el contexto en el que se desarrollaría el trabajo escenográfico:

La decoración del $2^{\circ}$ cuadro representa la Torre del homenaje del Alcázar de Sansueña, con fondo y grandes lejanías. Melisendra aparece asomada a un balcón de la torre. Un moro de aspecto grave y ricamente vestido — el Rey Marsilio - hace diferentes apariciones por una galería exterior del Castillo, y que supones conduce a la Torre del Homenaje. Melisendra es sorprendida por un moro que le da un beso en mitad de los labios. El Rey Marsilio manda prender al moro (Guardias del Rey Marsilio).

Como recordará Ud. deseo que tanto la decoración de este cuadro como los personajes (teatro planista) sean inspirados por los frescos de la Sala de la Justicia (color, indumentaria, etc.). Por excepción, no hay que seguir la indicación de Cervantes sobre la indumentaria mora de Melisendra ${ }^{29}$.

El trabajo escenográfico en esta producción, junto a Hernando Viñes y Manuel Ángeles Ortiz, supuso sin duda la consolidación de Lanz como consumado especialista en el ámbito del títere.

Tras el estreno escénico en París de El retablo, Lanz continúa su trayectoria como escenógrafo mediante su implicación directa en dos de los grandes proyectos profesionales de Manuel de Falla: el estreno escénico de El retablo en España y su posterior gira nacional, junto a la Orquesta Bética de Cámara. Lanz se encargará de tallar y pintar todos los títeres, esta vez en una escala constructiva natural, así como de adquirir competencias plenas en el aspecto escenográfico ${ }^{30}$, coordinando tramoya, telones, decorados, figuras planas, vestuario, iluminación y diseño del mecanismo que permitiría el movimiento de los muñecos durante la representación de la obra ${ }^{31}$.

El viernes 30 de enero de 1925 tiene lugar en el Teatro San Fernando de Sevilla la representación escénica de El retablo de maese Pedro en España. A continuación, se resume el equipo técnico y el reparto de tareas escenográficas, según las funciones reflejadas en el programa de mano ${ }^{32}$.

Equipo técnico:

Construcción del teatro portátil, pintura, maquinaria y resolución de aspectos técnicos del teatrillo a cargo de Lanz.

Croquis para fachadas, embocaduras y telones del teatro y del retablo, diseñados por Ángeles Ortiz.

${ }^{29}$ Carta de Falla a Lanz, París, 28 de abril de 1923, AMF (carpeta de correspondencia 7929).

${ }^{30}$ AA.VV., 1993: 11.

31 AA.VV., 1993: 10-11.

32 Programa de mano correspondiente al estreno de El Retablo de maese Pedro (30 de enero) 1925, AMF, 3, FN. 
- Ocho títeres articulados con cabezas de cartón pintadas con colores intensos, obra de Hermenegildo Lanz. En el programa de mano pone "cabezas esculpidas", pero por las entrevistas y correspondencia sabemos que se trataba de cabezas modeladas en cartón piedra (Figura 3).

- Trajes confeccionados según figurines de Ángeles Ortiz y Viñes.

- Figuras planas y escenografías para la historia de la libertad de Melisendra en el retablo:

- Cuadro $1 .^{\circ}$ Sala del Palacio de Carlo Magno: según dibujos de Ángeles Ortiz.

- Cuadro 2. ${ }^{\circ}$ Torre del Alcázar de Sansueña (Zaragoza): según decorados y figuras de Lanz.

- Cuadro 3. ${ }^{\circ}$ Plaza pública de la Ciudad de Sansueña: según dibujos de Viñes.

- Cuadro 4. ${ }^{\circ}$ Los Pirineos: según dibujos de Ángeles Ortiz.

- Las escenografías de los cuadros $5 .^{\circ}$ y $6 .^{\circ}$ son las mismas que las de los cuadros $2 .^{\circ}$ y $3 .^{\circ}$ Las figuras planistas de estos cuadros son autoría de estos mismos artistas respectivamente.

- Movimiento escénico de las figuras planistas del retablo y de los títeres "muñecos-guiñol”, a cargo de músicos de la Orquesta Bética ${ }^{33}$.

En 2012, con motivo de una exposición en el Parque de las Ciencias de Granada sobre la compañía del nieto de Lanz, salieron a la luz unos bocetos inéditos que la familia de Lanz encontró dentro de un libro; al parecer se trataba de otro proyecto de teatro de títeres junto a Falla y Lorca titulado Cuento de brujas, y en uno de los bocetos se observan manuscritas las siguientes palabras de Lanz:

Escena Primera. Interior antiguo, siglo XVII. Chimeneas a la derecha del espectador, un pozo al fondo, bancos, mesa, escaños, cornucopias, y todo lo que caracteriza una casa de viejos hidalgos temerosos del Poder Oculto. La abuelita refiere al nieto viejos cuentos de aparecidos, brujas y duendes. La madre hace labores, el padre lee.

Es hora de ánimas, el niño es llevado a la cama por su nodriza.

El color de esta escena es todo lo brillante que permita la hoguera y un velón que está sobre la mesa. La abuelita de negro riguroso con blancos cabellos, se destacará sobre el fondo de fuego del hogar, el niño de pie ante ella escucha atentamente. Los padres junto a la mesa, él de azul oscuro, gola blanca, ella amarillo, gola blanca, la nodriza refajo con vivos negros ${ }^{34}$.

El manuscrito también incluye otras referencias a los colores de la escena, las cuales coinciden con los apuntes que se conservan en el Archivo Lanz (Figura 4).

${ }^{33}$ Durante la gira nacional se estropea el mecanismo del teatrito debido a un mal uso por parte de los músicos que, ante la falta de presupuesto, terminaron haciendo las manipulaciones.

${ }^{34}$ Notas de Hermenegildo Lanz, texto original manuscrito, Granada, (AL). 
"Estas dos últimas escenas [nos dice] han de dar, de color y calidad, la sensación de un aguafuerte negro con grandes contrastes de claroscuro y luminosidad" 35 .

Muy probablemente estos apuntes estén en conexión con la carta que durante el verano de 1923 Lorca escribe al poeta José de Ciria y Escalante: "Preparamos Falla y yo la segunda representación de los títeres de Cachiporra, en la que representaremos un cuento de brujas, con música infernal de Falla y además colaborarán Halffter y Adolfito Salazar" "36. Con relación a este montaje se conservan treinta dibujos de Lanz y varios folios manuscritos con las líneas del argumento (sin autor) y detalles sobre color, iluminación y ambientación.

La afición de Falla por los títeres no solo era algo conocido por su círculo de amigos y colaboradores, era algo que muchos de ellos compartían. Tal era el caso de Santiago Rusiñol, que participará de modo entusiasta en toda la organización del Concurso de Cante Jondo de Granada en 1922, y que por entonces ya había escrito y estrenado una obra de polichinelas, personaje principal de la commedia dell'arte, que protagonizaría el títere catalán más tradicional, Titella. También Zuloaga ${ }^{37}$, colaborador de Falla en múltiples proyectos, era un gran aficionado a los títeres ${ }^{38}$.

En la composición de El retablo de maese Pedro, Cervantes describe el espectáculo que protagonizan don Quijote y maese Pedro dentro de la novela, recogido, en el capítulo XXvi de su segundo volumen. No obstante, Cervantes no mostraba mucha devoción por el oficio del titiritero, del cual daría cumplida cuenta en El coloquio de los perros, así como en El licenciado Vidriera y las Novelas ejemplares, de este modo:

... de los titereros dezía mil males; dezía que era gente vagamunda y que trataba con indecencia de las cosas divinas, porque con las figuras, que mostraban en sus retablos, volvían la devoción en risa...

... gente vagamunda, esponjas del vino y gorgojos del pan $^{39}$.

Las colaboraciones escénicas entre Falla y Lorca de índole titiritesca tuvieron continuidad en otro proyecto frustrado, Lola la comedianta, que se gestaría entre

${ }^{35}$ Notas de Hermenegildo Lanz, texto original manuscrito, Granada, (AL).

36 García Lorca, 1997: 200.

37 Véase: Museo Nacional del Teatro, Almagro (Ciudad Real). Además de otro material de interés, en este museo se conservan los títeres que Zuloaga construyó para la representación en 1928 de El retablo en la Ópera Cómica de París.

38 Véase AA.VV., 2016: 105-185. Se trata del capítulo titulado "Un acercamiento a El retablo de maese Pedro de Manuel de Falla e Ignacio Zuloaga”, autoría de José vallejo Prieto. Por otra parte, el AMF alberga un gran legado de la correspondencia entre ambos artistas, la cual se puede consultar además en el volumen Correspondencia entre Falla y $\mathrm{Zu}$ loaga (1915 y 1942), que editó el Ayuntamiento de Granada.

${ }^{39}$ Cervantes Saavedra, 2017: 23. 
1922 y 1924, en forma de opereta y que, según la escasa información contenida en el primer manuscrito, se había planteado como una obra inspirada en la tragicomedia de Don Cristóbal y la señá Rosita, protagonistas de un teatro de muñecos ${ }^{40}$.

El universo titiritesco tan querido por Lorca y Falla no puede entenderse en España sin abordar las figuras de Manuel Fontanals, vinculado al gran titiritero Ezequiel Vigués, apodado Didó, a producciones de Lorca en el género, y principalmente a Bartolozzi ${ }^{41}$. Este último sería el creador de algunos de los títeres y personajes infantiles que marcaron a generaciones de niños en España. Su legendario teatro de marionetas, modernista, pero de sencilla factura, recibió el nombre de Teatro Pinocho, presentando a través de él un mundo de fantasía, ingenuo, primitivo y gracioso, donde los pequeños idealizarían a su nuevo héroe nacional, Pinocho, que siempre saldría triunfante en las luchas contra su eterno rival, Chapete, en aventuras que incluían a Pulgarcito, Barba Azul, Cenicienta o Caperucita. Su teatro recorrió toda España y sus muñecos se convirtieron en leyendas y símbolos de generaciones, más allá de sus regulares colaboraciones con personalidades como Lorca, Margarita Xirgu, Rivas Cherif, Alberti o Jacinto Benavente.

De Bartolozzi no podemos obviar su internacionalmente aclamada producción de El retablo de maese Pedro, que estrenó durante su exilio en México. También durante esta etapa, Bartolozzi diseña la escenografía y construye los títeres para La zapatera prodigiosa de Lorca. Por su vinculación al ámbito guiñolesco nacional, además de por la labor escenográfica y de indumentaria de Bartolozzi, ha pasado asimismo a la historia de este tipo de espectáculos La reina castiza de Valle-Inclán, estrenada el 4 de junio de 1931 en el Teatro Muñoz Seca de Madrid ${ }^{42}$.

La Residencia de Estudiantes, institución intrínsecamente unida al ideario cultural y formativo de la República, siempre atenta a las vanguardias artísticas, también participaría en la organización de espectáculos de títeres. Más allá de la problemática derivada del intento de programar en versión escénica El retablo de maese Pedro, entre estas producciones titiriteras vinculadas a la institución destaca la producción de Historia de un soldado de Stravinsky, el 11 de junio de 1931. Con unos títeres confeccionados y manipulados por Eva Aggerholm, en la producción también colaborarían Vázquez Díaz en el ámbito escenográfico-plástico y Rivas Cherif en el escénico ${ }^{43}$.

El retablo de maese Pedro exigía en su puesta en escena no solamente un trabajo en el ámbito de la escenografía y la indumentaria, también en lo que se

${ }^{40}$ Porras Soriano, 1995: 164

${ }^{41}$ Sobre la relación de Bartolozzi con los títeres véase: Vela Cervera, 1996.

Sobre la relación entre Bartolozzi y Falla, véase: Gibson, 1985: 239-242. Gibson documenta la presencia de Salvador Bartolozzi y su hermana, en el ensayo de El amor brujo, de Manuel de Falla. También asistió al ensayo García Lorca.

42 Porras Soriano, 1995: 347.

${ }^{43}$ Porras Soriano, 1995: 349. 
refiere a la fabricación de los títeres que son los protagonistas de las historias que transcurren durante la obra. Además de los títeres proyectados por Lanz y Zuloaga, también conservamos algunos de estos muñecos construidos por marionetistas alemanes e italianos y de gran calidad en su manufactura. De estos artesanos cabría destacar por su belleza y buen acabado los títeres realizados por Fischer, comúnmente conocidos como Los muñecos de Zúrich, puesto que se utilizaron por primera vez en la representación de El retablo el 20 junio de 1926 y que actualmente están conservados en el Museo Suizo de Marionetas de Zúrich. La representación en la ciudad suiza implica asimismo la supervisión directa de Falla, dentro del Festival de la Sociedad Internacional de Música Contemporánea (SIMC).

El retablo y sus títeres logran en pocos años reconocimiento internacional, representándose, tras el estreno en Francia en 1926, en Nueva York, Zúrich o Ámsterdam. En 1927 se lleva a Londres en versión de concierto y en 1928 a Siena, es retransmitido por la BBC con dirección orquestal del propio Falla en 1931 y triunfa en el Festival de la SIMC en Venecia en $1932^{44}$. Para esta representación el director del teatro llega a solicitar a la Princesa de Polignac la cesión de las cabezas que Lanz talló para los títeres del estreno parisino de 1923, así como los vestuarios y escenografías. Sin embargo, el amplio escenario que albergaría la reposición, frente a las reducidas dimensiones del salón de la Princesa, hacen que la idea sea descartada por Falla, opinando que las marionetas eran demasiado pequeñas. Una vez más se observa el buen criterio del compositor gaditano y conocimiento de la escena. Finalmente, no se crearían nuevas marionetas, sino que se reutilizarían las talladas por Fischer para la representación de la obra en Zúrich de 1926 (Figura 5). Estos mismos títeres de Fischer viajarían en 1932 con motivo del estreno en Venecia de El retablo, representación de la que se conserva material gráfico de Falla posando junto a los mismos. Todos estos títeres fueron tallados en madera con un acabado extremadamente delicado y detallista, alcanzando una calidad casi escultórica, frente al carácter y manufactura más rústicos de los títeres de Lanz y Zuloaga.

La utilización de estos mismos títeres de Fischer para la representación veneciana se debió a no poderse satisfacer el deseo de Falla de que el encargado de su construcción fuera el marionetista y empresario escénico Podrecca, fundador del Teatro dei Piccoli, compañía referente de la vanguardia escénica, compuesta por ciento veinticinco personas y mil doscientos títeres. Podrecca fundó su Teatro dei Piccoli en 1914. Abogado de profesión y melómano de vocación, a partir de ese momento diseña toda una serie de espectáculos escénicos interdisciplinares que cuentan con el concurso de los artistas más vanguardistas del momento y que triunfarían allá donde viajaran durante medio siglo, e influyen a su vez en

${ }^{44}$ Miermont/Gobin, 2003: 73.

LABORATORIO DE ARTE 33 (2021), pp. 361-382, ISSN 1130-5762 e-ISSN 2253-8305 - DOI http://dx.doi.org/10.12795/LA.2021.i33.18 
otros muchos artistas contemporáneos, como sería el caso de Valle-Inclán, Rivas Cherif o Lorca.

Sería a finales de 1924 cuando actuarían por primera vez en España los títeres de Podrecca y su Teatro dei Piccoli. La compañía contaba con los mejores profesionales y constructores en este género escénico. Más allá de las diferentes propuestas escénicas vinculadas a El retablo de maese Pedro y los títeres protagonistas de la obra en las representaciones de París, Sevilla -como parte de la gira española de 1925-, Ámsterdam, Zúrich, Venecia, etc., las figuras de Podrecca y Lanz en el universo titiritero de Falla son fundamentales por sus aportaciones a la historia del teatro en España, Europa y Latinoamérica.

La producción de El retablo de maese Pedro que organizó Podrecca junto a Falla en 1942 durante el exilio del compositor gaditano en Argentina es reconocida estudiosos de la obra como la que gozó de más consideración por parte del propio Falla ${ }^{45}$. En esta aventura de El retablo, obra maestra en el mundo de la vanguardia artística europea, no olvidó Falla a su otro gran titiritero, su incondicional amigo y colaborado Lanz, que sería además pionero en la reivindicación como género artístico del teatro de papel, y que influyó muy significativamente en otros creadores y titiriteros contemporáneos ${ }^{46}$.

Manuel de Falla ciertamente funcionó como nexo y centro en torno al cual orbitaron diversos artistas, que no se denominaban a sí mismos escenógrafos en la mayoría de los casos, como Lanz, Ángeles Ortiz, Viñes o Zuloaga. Mediante el presente artículo se ha recuperado parte de su legado como fragmentos intrínsecos de la historia de la escenografía y el títere en la España de principios del siglo XX.

Por otra parte, El retablo de maese Pedro, supone un salto cualitativo en lo que a las formas tradicionales y a la búsqueda de nuevas fórmulas escénicas respecta; en ese sentido comulga con los postulados de Craig, en relación con la «supermarioneta» y el uso de figuras inanimadas en sustitución de la figura del actor.

Fecha de recepción: 22 de octubre de 2020.

Fecha de aceptación: 2 de mayo de 2021.

${ }^{45} \mathrm{http}: / / \mathrm{www}$. titeresante.es/2016/08/18/la-europa-de-las-vanguardias-proyecto-allstrings-attached-klemencic-podrecca-y-lanz-pioneros-de-los-titeres-europeos-por-yanisb (27/04/2021). García-Abad, 1997: 145.

${ }^{46} \mathrm{http} / / / w w w . t i t e r e s a n t e . e s / 2016 / 08 / 18 /$ la-europa-de-las-vanguardias-proyecto-allstrings-attached-klemencic-podrecca-y-lanz-pioneros-de-los-titeres-europeos-por-yanisb (27/04/2021). 


\section{BIBLIOGRAFÍA}

AA.VV. (1993): Hermenegildo Lanz. Escenógrafo. Las experiencias teatrales en los años 20 granadinos (1922-1936). Granada: Archivo Manuel de Falla.

- (2016): Zuloaga-Falla. Historia de una amistad. Granada: Patronato de la Alhambra y el Generalife.

Calderón Calderón, Manuel (2000): "El retablo de títeres: un teatro de vanguardia en España (1909-1937)". En: Anuario brasileño de estudios hispánicos, 10, pp. 187-204.

Castillo Higueras, José Miguel (1994): Hermenegildo Lanz. Granada y las vanguardias culturales (1917-1936) [catálogo de la exposición]. Granada: Archivo Manuel de Falla y Ayto. de Granada.

Cervantes Saavedra, Miguel de (2017): El Licenciado Vidriera, ed. Agustín Moreto y Cabaña. Barcelona: Linkgua digital.

Christoforidis, Michael (1997): Aspects of the Creative Process in Manuel de Falla's El retablo de Maese Pedro and Concerto. The University of Melbourne.

Falla, Manuel de/Trend, John B. (2007): Epistolario (1919-1935). Granada: Universidad de Granada/Archivo Manuel de Falla.

Francés, José (1923): "Los bellos ejemplos. En Granada resucita el guignol”. En: La Esfera, 475, [artículo sin paginación].

García-Abad García, María Teresa (1997): "El Teatro dei Piccoli de Vittorio Podrecca o la ruptura de los límites estéticos". En: Revista de estudios teatrales, 11, pp. 135-153.

García Lorca, Federico (1997): Epistolario completo. Madrid: Cátedra.

Gibson, Ian (1985): Federico García Lorca. De Fuentevaqueros a Nueva York, 1898-1929. Barcelona: Grijalbo.

Malipiero, Francesco/Soria Ortega, Andrés/Sopeña Ibáñez, Federico (1983): Manuel de Falla (Evocación y correspondencia). Granada: Ed. Universidad de Granada, 1983.

Martínez, Yanisbel (2016a): "En busca de la niña que riega la albahaca”. En: Fantoche, Arte de los titeres, 19, pp. 102-124.

(2016b): "La Europa de las Vanguardias. Proyecto ALL STRINGS ATTACHED - Klemenčič, Podrecca y Lanz: pioneros de los títeres europeos". En: Titeresante. Revista de titeres, sombras y marionetas. En http:// www.titeresante.es/2016/08/18/la-europa-de-las-vanguardias-proyecto-allstrings-attached-klemencic-podrecca-y-lanz-pioneros-de-los-titeres-europeos-por-yanisb (27/04/2021).

- (2012): "Hermenegildo Lanz y los títeres". En: Martínez, Yanisbel (ed.): Títeres, 30 años de Etcétera. Granada: Parque de las Ciencias, pp. 28-47.

Mata, Juan (2003): Apogeo y silencio de Hermenegildo Lanz. Granada: Diputación de Granada/Los libros de la Estrella. 
Miermont Beaure, Juan/Gobin, Alain (2003): Hernando Viñes / Manuel de Falla. Paris: Association Hernando Viñes, Cahiers de l'Association Hernando Viñes. Mora Guardino, José (1923): "Crónicas Granadinas. El teatro cachiporra andaluz". En: $L a$ Voz [artículo sin paginación del 12 de enero].

Pahissa, Jaime (1947): Vida y obra de Manuel de Falla. Buenos Aires: Ricordi Americana.

Porras Soriano, Francisco (1995): Los títeres de Falla y García Lorca. Madrid: UNIMA.

Soria Ortega, Andrés (2000): "Hermenegildo Lanz en la Granada de su tiempo". En: Príncipe de Viana, 18, pp. 393-404.

Vela Cervera, David (1996): Salvador Bartolozzi (1881-1950): Ilustración gráfica. Escenografía. Narrativa y teatro para niños. Zaragoza: Universidad de Zaragoza (Tesis Doctoral). 

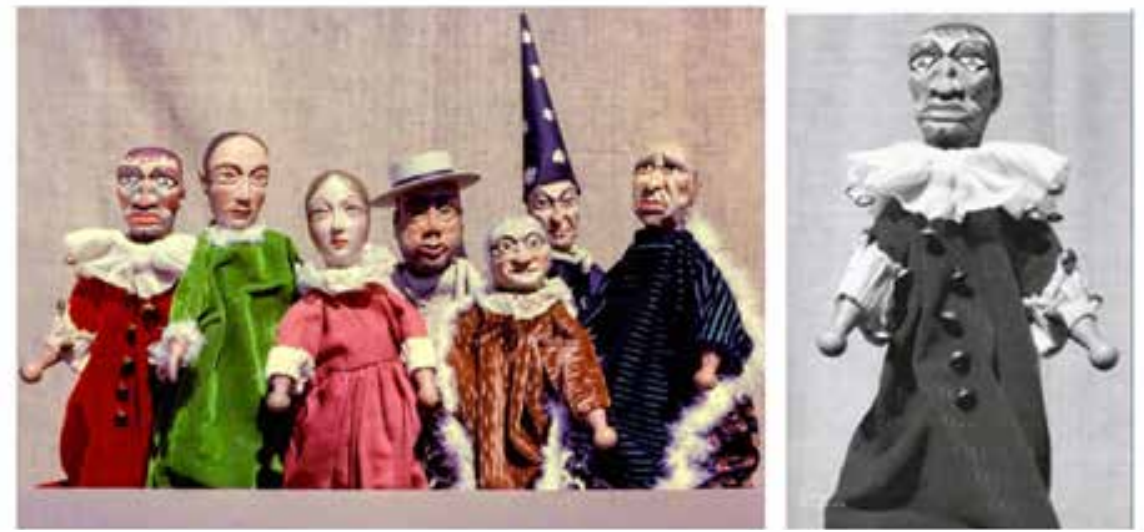

Figura 1: Hermenegildo Lanz, Títeres para la representación Títeres de Cachiporra,

(Cristobica) Detalle de la figura de Don Cristóbal, 1923, Archivo Lanz.
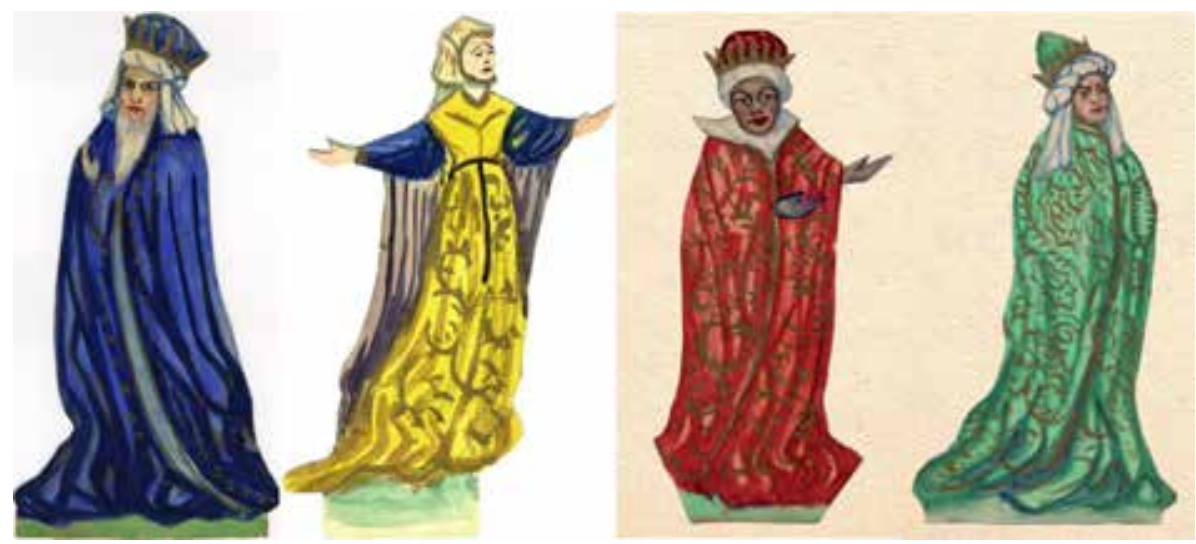

Figura 2: Hermenegildo Lanz, Figuras planistas para El misterio de los Reyes Magos, 1923, Archivo Lanz. 


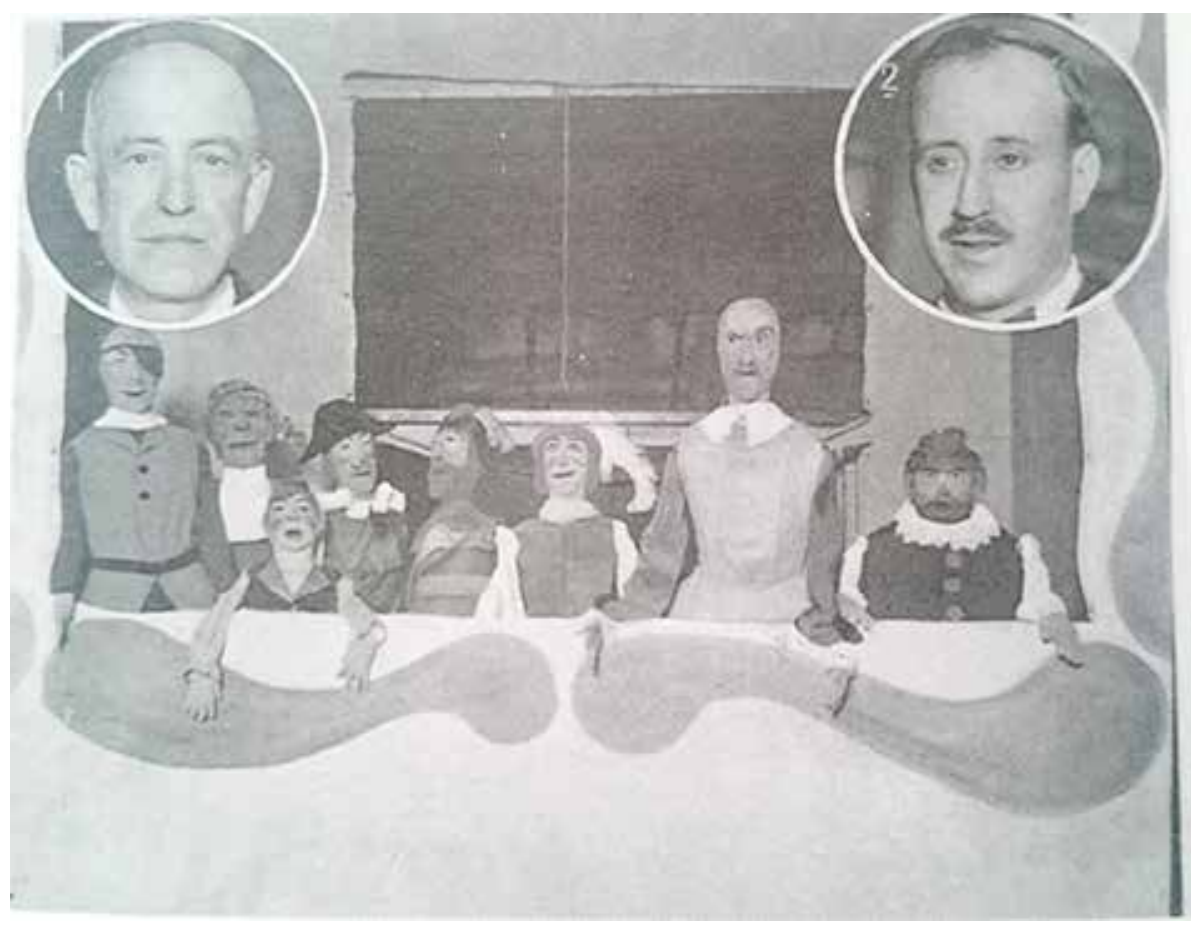

Figura 3: Hermenegildo Lanz [Fotografía de Sánchez del Pando], Los muñecos del Retablo de Maese Pedro, 1925. En: El Liberal, Sevilla (30 de enero), p.1. 


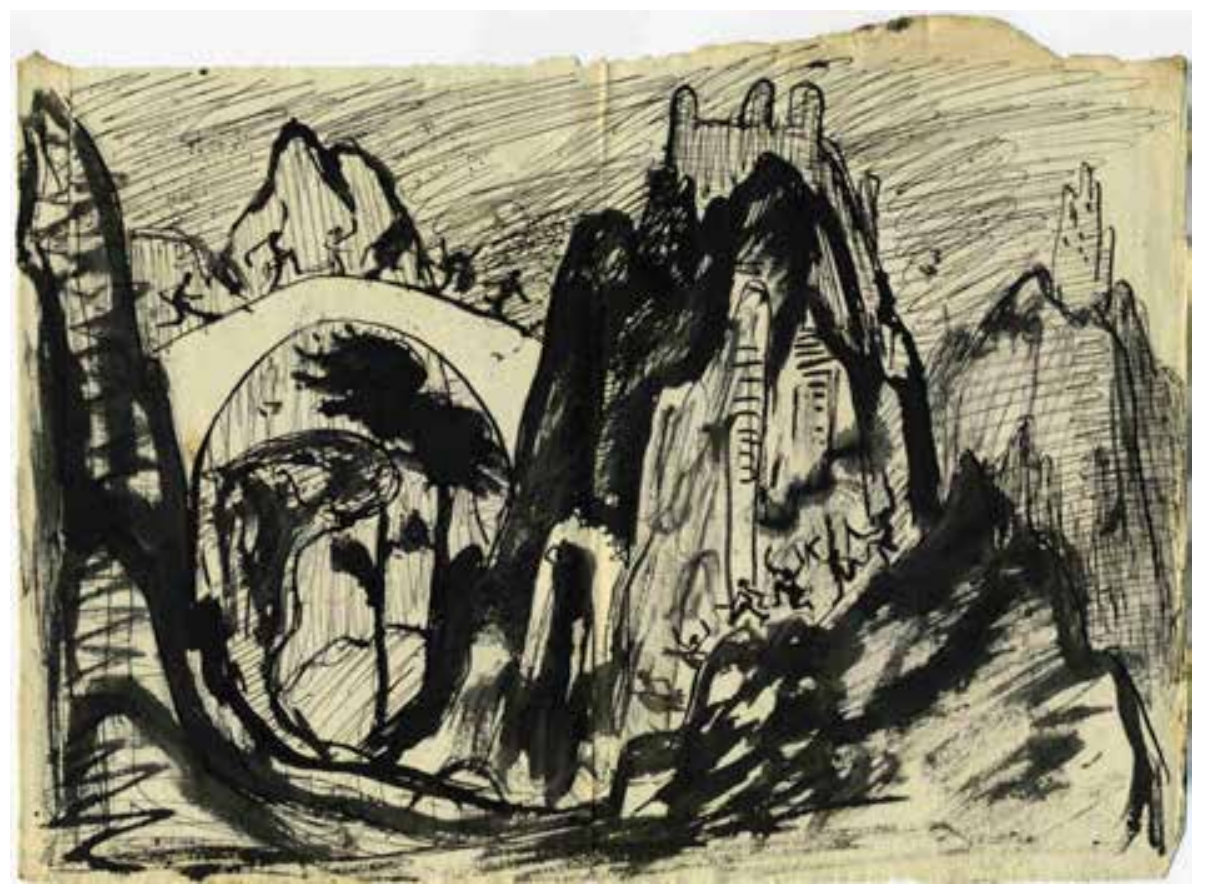

Figura 4: Hermenegildo Lanz, Bocetos para una escenografía sobre un cuento de brujas, ca. 1923, Archivo Lanz. Imágenes extraídas de: Elsa Fernández-Santos, "Aquel titiritero a la vera de Lorca”. En: El País, Madrid (30 de mayo 2012). 


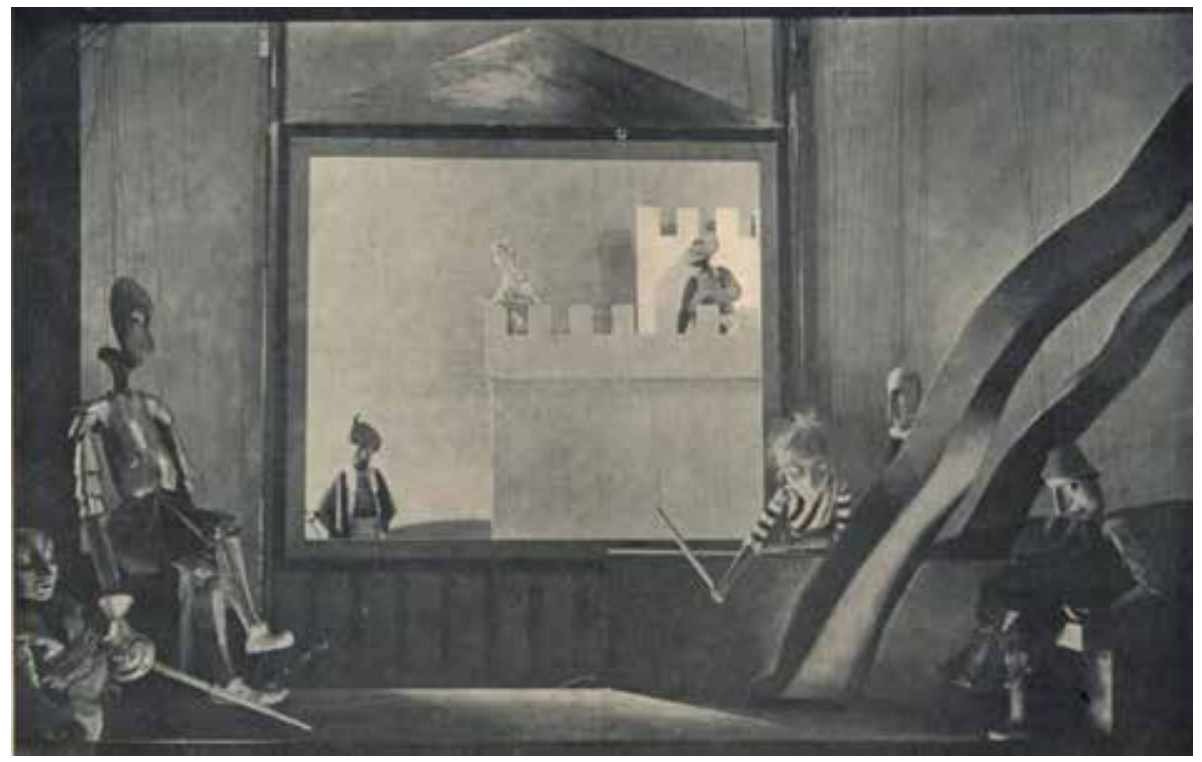

Figura 5: Carl Fischer [títeres y escenografía], Representación de "El retablo de Maese Pedro" en Zurich, 1926, MAE (Centre de Documentació i Museu de les Arts Escèniques) Institut del Teatre. Ref.: 259290. 